\title{
Study on the Instability Mechanism and Control Measures of a Roadway in a Mine with Retained Coal Pillars and Close Coal Seams
}

\author{
Huai-Qian Liu $\mathbb{D}^{1,2}$ Lei Wang $\mathbb{D}^{1},{ }^{2}$ Lian-Chang Han, ${ }^{3}$ Ping Liu, ${ }^{4}$ and Peng $\mathrm{Zou}^{2}$ \\ ${ }^{1}$ School of Energy and Mining Engineering, China University of Mining and Technology (Beijing), Beijing 100083, China \\ ${ }^{2}$ State Key Laboratory Mine Response and Disaster Prevention and Control in Deep Coal Mine, \\ Anhui University of Science and Technology, Huainan 232001, China \\ ${ }^{3}$ Guizhou Panjiang Clean Coal Company Limited, Panzhou 553536, China \\ ${ }^{4}$ Mining College, Guizhou University, Guiyang 550025, China \\ Correspondence should be addressed to Lei Wang; leiwang723@126.com
}

Received 15 September 2020; Revised 6 November 2020; Accepted 4 December 2020; Published 4 January 2021

Academic Editor: Xuesheng Liu

Copyright (C) 2021 Huai-Qian Liu et al. This is an open access article distributed under the Creative Commons Attribution License, which permits unrestricted use, distribution, and reproduction in any medium, provided the original work is properly cited.

\begin{abstract}
The deformation and instability of roadway surrounding rock reflect the processes of energy accumulation and release. To reveal the instability of roadway surrounding rock, based on the engineering geological conditions of a certain mine, this paper established a nonuniform superimposed stress model of a coal pillar, starting from the energy accumulation and release of the surrounding rock of the floor roadway after coal pillar failure. The essence of the deformation of the lower roadway was revealed, and the following conclusions were drawn: (1) The elastic strain energy accumulated in the lower roadway roof and upper coal pillar is related to not only the physical properties of the coal seam but also the distance between the coal pillar and surrounding rock, the caving height and shape, the burial depth, and the retained pillar width. (2) The elastic strain energy accumulated in the lower roadway roof and the upper coal pillar induced large displacements of the roadway due to the energy release during excavation. (3) It is proposed that the "stress relief degree" and failure morphology are used to identify zones in the rock and coal, and the two zoning modes have a high consistency. (4) The stress distribution in a narrow coal pillar should be calculated in segments. (5) Based on the zoning and energy release characteristics, the following control factors are suggested regarding the coal pillar width and roadway layout: (a) for the coal pillar, avoid the overlap or intersection of the peak values in the limit equilibrium zone and ensure a sufficient elastic zone; (b) arrange the roadway in shear slip Zone B-2 or the moderate pressure relief Zone B-2 to reduce the accumulation of elastic strain energy in the surrounding rock.
\end{abstract}

\section{Introduction}

Closely spaced coal seams (close coal seams) are quite common in China [1], and a large proportion are mined [2], such as at Datong and Lianghuai and Liupanshui [3-6]. With the increase in mining depth or intensity, the instability of the mining roadway caused by this phenomenon becomes more serious. If the interval between coal seams is relatively small, the roadway excavation and coal seam mining can be unstable, which results in the failure of the coal pillar in the upper coal seam and floor damage, and the integrity and coordination of the lower coal seam roof are destroyed. The resulting high stress or high energy is transferred to the lower roadway due to the damage of the coal pillar and floor, which leads to instability and deformation of the mining roadway.

At present, many scholars have performed a considerable amount of research on the deformation and instability of lower mining roadways: Xu et al. [7] used numerical simulation and theoretical analysis to study the evolution characteristics of the stress deviation in the floor under a pillar after mining in an upper coal seam, revealed the mechanical control of roadway surrounding rock deformation, proposed roadway control measures, and achieved a good engineering 
application effect; Zhang et al. [3], Hu et al. [8], and Zhang et al. [9], respectively, analyzed the stress distribution characteristics of the coal pillar floor after mining an upper coal seam, proposed the stress change rate coefficient, also known as the stress field change rate coefficient, to measure the stress uniformity index, and concluded that the stress distribution of the coal pillar floor showed significant nonuniformity, which led to stress concentration in the roof of the mining roadway. Gao et al. [10] found that as the advanced coal body got closer to overlying coal pillar, the stress exerted a significant influence on the surrounding rock deformation by numerical simulation and field test. Gao et al. [11] used numerical simulation to study deformation of the lower return-air roadway under the complex stress of the upper gob and the retained coal pillar and determined that the $8 \mathrm{~m}$ coal pillar can effectively control the deformation of the lower return-air roadway. Zhang et al. [12] used numerical simulation and theoretical analysis to study the floor damage depth and determined the optimal location and layout of the roadway. By means of simulation, Wang et al. [13] obtained that the elastic strain energy accumulated in the roof and upper coal pillar will induce the instability and deformation of a roadway due to the energy release and may even cause a dynamic disaster when the lower coal seam and rock mass is suddenly destroyed. Although the above research results have greatly enriched the theory of deformation failure and surrounding rock control of floor roadways, the mechanism of surrounding rock deformation caused by a nonuniform superimposed stress in the retained coal pillars in close coal seam roadways is still unclear. Therefore, to provide scientific decision-making and theoretical guidance to maintain the stability of lower mining roadways, in this paper, the authors simplify the superimposed stress model of a coal pillar, considering the mechanism of energy accumulation and release after the pillar failure, and then discuss rational suggestions for the size of the retained coal pillars in the upper coal seam and the arrangement of the mining roadway.

\section{Analysis of the Failure Characteristics of the Roadway under the Goaf}

2.1. Engineering Geology Conditions. The $1118_{1} 3$ mining face is located in the second section of the \#181 coal seam of a mine. The depth of burial is $240 \mathrm{~m}$. The coal seam dip angle ranges from $5^{\circ}$ to $12^{\circ}$, which corresponds to a near-horizontal mining face. The strike length of the mining face is $817 \mathrm{~m}$ to $825 \mathrm{~m}$, the dip length is $82 \mathrm{~m}$, and the coal seam thickness is $2.0 \mathrm{~m}$ to $3.2 \mathrm{~m}$, with an average thickness of $2.6 \mathrm{~m}$. The coal is relatively hard. There is occasionally banded pyrite in the middle and upper parts of the coal seam with 0 to 2 layers of gangue, which is mostly brown carbonaceous mudstone or light gray mudstone. The 11173 and 11175 mining faces in the overlying \# 17 coal seam have been mined out, and the width of the coal pillar is $8 \mathrm{~m}$. There is no engineering structure in the underlying \#18 coal seam. The roadway layout, coal seam location, and rock properties of the roof and floor are shown in Figure 1. The roof and floor of the coal seam are interbedded argillaceous fine sandstone and mudstone, other types of fine sandstone and mudstone,

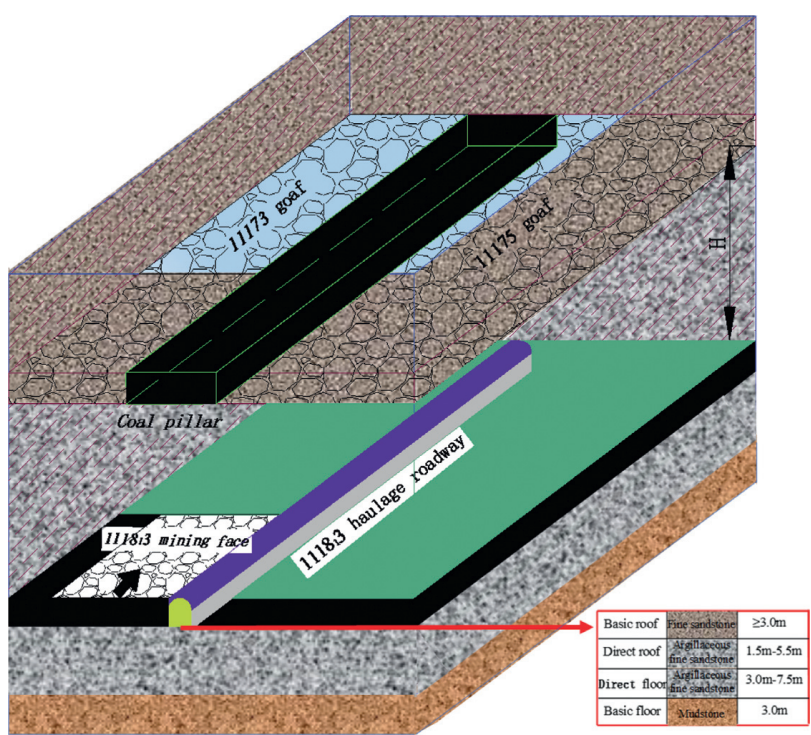

Figure 1: Diagram of the roadway layout.

and the floor is interbedded argillaceous fine sandstone and mudstone. The roadway adopts the mixed arrangement layout, and the horizontal distance between the $1118_{1} 3$ haulage roadway and 11173 haulage roadway is approximately $5 \mathrm{~m}$. The vertical distances to these roadways from the \#17 coal seam are $6.5 \mathrm{~m}$ to $9.6 \mathrm{~m}$, with an average vertical distance of $8 \mathrm{~m}$.

The shape of the $1118_{1} 3$ haulage roadway is a straightwalled semicircular arch with an excavation size of $4800 \mathrm{~mm} \times 800 \mathrm{~mm}$ (the width at the bottom $\times$ the height at the center). As shown in Figure 2, the roadway underwent obvious deformation during excavation and mining, and the specific deformation failure characteristics are as follows:

(1) The deformation and failure of the roadway have occurred over a long time, and the roof and floor of the roadway are seriously deformed; even local roof fall has been observed

(2) The failures of many structural elements have been observed; for example, bolts and anchor cables have broken, trays and bolt bodies have separated, and steel mesh and trays have been cut off

2.2. Analysis of the Failure Depth of the Coal Seam Floor. The failure depth of the floor caused by coal mining is generally obtained by the foundation calculation method from soil mechanics [14-16], and according to plastic theory and mining pressure theory $[17,18]$, the limit equilibrium zone in the foundation is divided into an active stress zone, transition zone, and passive stress zone, as shown in Figure 3.

\subsubsection{Active Stress Zone (Zone I')}

$$
\angle C A B=\angle C B A=\frac{\pi}{4}+\frac{\varphi}{2},
$$




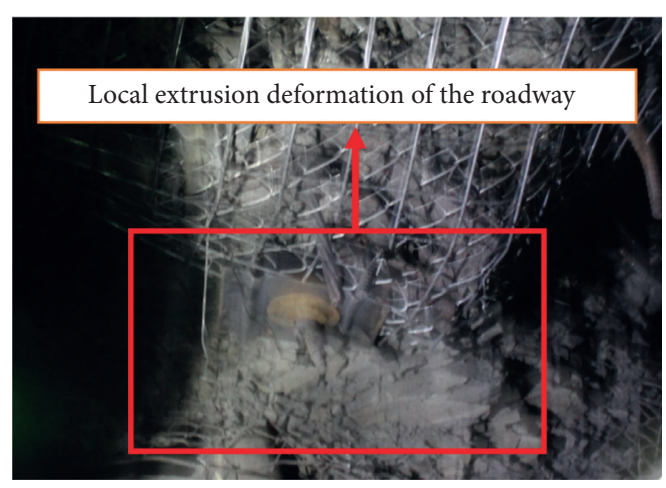

(a)

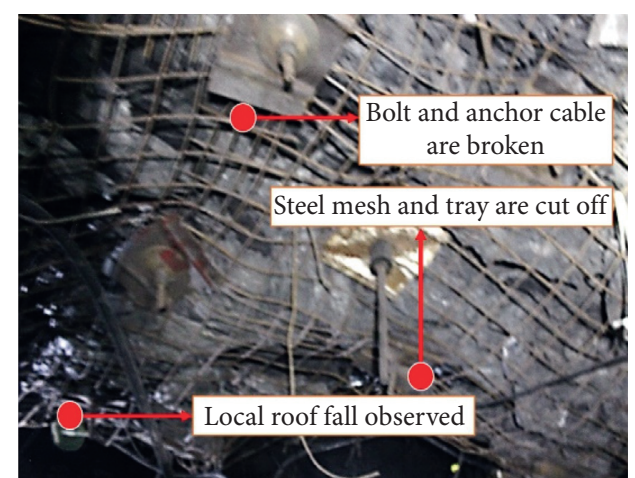

(b)

Figure 2: Actual deformation of the haulage roadway.

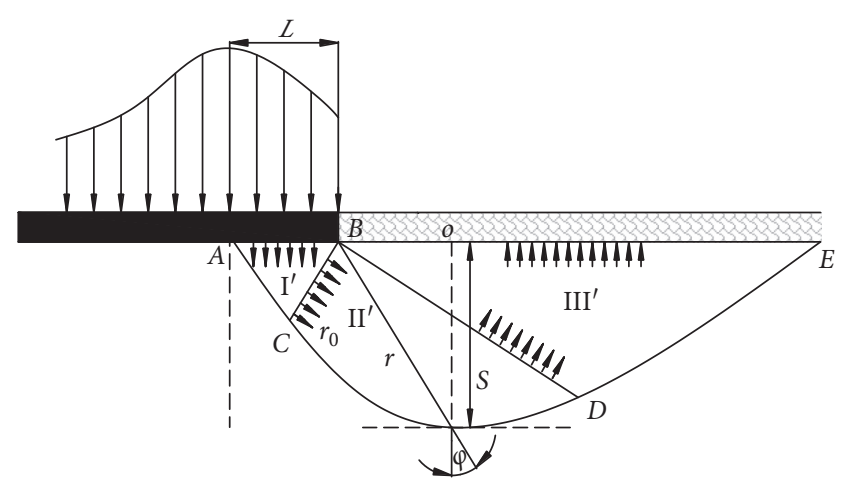

Figure 3: Mechanical model of floor failure caused by abutment pressure.

where $\varphi$ is the friction angle between the top and bottom of the coal seam and is assumed to be $38^{\circ}$ here.

2.2.2. Transition Zone (Zone $\left.I I^{\prime}\right)$. The $C D$ curve is a logarithmic spiral with $A$ as the origin, and the spiral equation (2) is as follows:

$$
r=r_{0} e^{\alpha \tan \varphi}
$$

where $r$ is the radius of the spiral at an angle $\alpha$ to $r_{0}$ with $A$ as the origin and $r_{0}$ is the length of $A C$ or $B C$.

\subsubsection{Passive Stress Zone (Zone III')}

$$
\angle B E D=\frac{\pi}{4}-\frac{\varphi}{2}
$$

From the geometric relationship in Figure 3, equation (4) is obtained:

$$
S=\frac{L e^{\alpha \tan \varphi} \cos (\alpha-(\pi / 4)+(\varphi / 2))}{2 \cos ((\pi / 4)+(\varphi / 2))},
$$

where $L=(m / 2 \xi f) \ln \left((K \prime \gamma H+c \cot \varphi \prime) / \xi\left(p_{1}+c \cot \varphi \prime\right)\right)$. $K^{\prime}$ is the stress concentration factor, which is 2.8 ; $\varphi^{\prime}$ is the friction angle of the coal seam, which is 2.8 ; $\xi$ is the triaxial stress coefficient, $\xi=\left(\left(1+\sin \varphi^{\prime}\right) /\left(1-\sin \varphi^{\prime}\right)\right) ; P_{1}$ is the resistance of the support to the coal side, which is $0.1 \mathrm{MPa} ; m$ is the thickness of the coal seam; $c$ is the coal seam cohesion, which is $0.8 \mathrm{MPa}$; and $f$ is the friction coefficient of the contact surface between the roof and floor of the coal seam, which is 0.1 .

Let $(\mathrm{d} S / \mathrm{d} \alpha)=0$; the maximum failure depth of the floor can be obtained:

$$
S_{\mathrm{Max}}=\frac{L \cos \varphi}{2 \cos ((\pi / 4)+(\varphi / 2))} e^{((\pi / 4)+(\varphi / 2)) \tan \varphi} .
$$

Substituting the above parameters into equation (5), the following is obtained: $S_{\mathrm{Max}}=23.66 \mathrm{~m}>8 \mathrm{~m}$. The calculation result shows that the failure range of the floor has spread to coal seam \#181 due to the mining of the \#17 coal seam.

Substituting the above parameters into equation (5), the following expression is obtained: $S_{\alpha=30}=7.54 \mathrm{~m}$. That is, the surrounding rock of the $1118_{1} 3$ haulage roadway does not undergo plastic failure.

2.3. Establishment of the Numerical Model. To reveal the stress distribution law of surrounding rock in the process of the deformation of the floor under the coal pillar, the authors take the geological conditions of the mine as the engineering background, and the finite difference software FLAC3D is used to establish a numerical model with a length of $320 \mathrm{~m}$ and a height of $200 \mathrm{~m}$. Considering the timeliness of computation, similar or thin rock strata are merged. The physical parameters of the rock strata considered here are shown in Table 1; the upper surface of the model is a free boundary, which is loaded with a uniform vertical compressive stress, and this boundary's displacement is fixed; the constitutive model adopts the Mohr-Coulomb constitutive model.

Coal seam mining changes the stress state of the surrounding rock, and the mining stress is redistributed with the advance of the mining face, which not only forms the stress concentration in the mining face but also transfers stress to the floor, resulting in a certain range of deformation and destruction of the floor strata [19]. Therefore, analyzing the stress distribution law of the floor under the pillar after the mining of the 11173 and 11175 mining faces plays an important role in the study of the deformation and failure of the haulage roadway in the lower $\# 18_{1}$ coal seam. 
TABLe 1: Physical parameters of the rock strata.

\begin{tabular}{|c|c|c|c|c|c|c|c|}
\hline Rock types & $\begin{array}{c}\text { Thickness } \\
(\mathrm{m})\end{array}$ & $\begin{array}{l}\text { Density } \\
\left(\mathrm{kg} / \mathrm{m}^{3}\right)\end{array}$ & $\begin{array}{c}\text { Bulk modulus } \\
(\mathrm{GPa})\end{array}$ & $\begin{array}{l}\text { Shear modulus } \\
(\mathrm{GPa})\end{array}$ & $\begin{array}{c}\text { Cohesion } \\
(\mathrm{MPa})\end{array}$ & $\begin{array}{c}\text { Friction } \\
\left({ }^{\circ}\right)\end{array}$ & $\begin{array}{l}\text { Tensile modulus } \\
(\mathrm{MPa})\end{array}$ \\
\hline Siltstone & 9.0 & 2460 & 10.82 & 8.20 & 2.75 & 35.0 & 1.8 \\
\hline Sandy mudstone & 1.0 & 2400 & 10.26 & 5.50 & 1.16 & 35.0 & 2.1 \\
\hline \#17 coal seam & 4.0 & 1380 & 1.78 & 0.83 & 0.80 & 27.0 & 0.4 \\
\hline Fine sandstone & 4.0 & 2600 & 14.26 & 11.50 & 2.66 & 38.0 & 3.5 \\
\hline $\begin{array}{l}\text { Interlayered sandstone } \\
\text { and mudstone }\end{array}$ & 4.0 & 2530 & 13.14 & 10.23 & 2.60 & 34.0 & 2.0 \\
\hline$\# 18_{1}$ coal seam & 2.6 & 1380 & 1.78 & 0.83 & 0.80 & 27.0 & 0.4 \\
\hline $\begin{array}{l}\text { Argillaceous fine } \\
\text { sandstone }\end{array}$ & 5.0 & 2460 & 11.62 & 8.73 & 2.60 & 34.0 & 3.2 \\
\hline Mudstone & 3.0 & 2483 & 6.08 & 3.47 & 1.23 & 30.0 & 0.7 \\
\hline \#18 coal seam & 2.1 & 1380 & 1.78 & 0.83 & 0.80 & 27.0 & 0.4 \\
\hline Mudstone & 1.0 & 2483 & 6.08 & 3.47 & 1.23 & 30.0 & 0.7 \\
\hline Siltstone & 5.0 & 2460 & 10.82 & 8.20 & 2.75 & 35.0 & 1.8 \\
\hline Mudstone & 13.0 & 2483 & 6.08 & 3.47 & 1.23 & 30.0 & 0.7 \\
\hline
\end{tabular}

The simulation scheme is as follows: first, calculate the initial equilibrium of the model under the given mechanical and displacement boundary conditions; second, excavate the 11173 and 11175 mining roadways; then, excavate the 11173 and 11175 mining faces in turn; and finally, excavate the $1118_{1} 3$ haulage roadway.

2.4. Failure Depth of the Floor and Failure Characteristics of the Lower Roadway. According to the distribution characteristics of the plastic zone in different stages of Figure 4, as shown in Figure 4(a), when the 11173 haulage roadway and 11175 return-air roadway in the upper coal seam are excavated completely, the failure height of the roadway roof is approximately $2.2 \mathrm{~m}$, the failure depth of the solid coal side is $2.2 \mathrm{~m}$, the failure depth of the coal pillar side is $2.1 \mathrm{~m}$, and the failure depth of the floor is approximately $2.6 \mathrm{~m}$. The mining roadway presents a symmetrical shear failure mode. As shown in Figure 4(b), when the 11173 mining face is mined out, the plastic failure zone of the coal pillar between the roadways forms a failure surface, which reflects tension-shear failure. The roof and floor of the mining face exhibit shear slip failures; the failure height of the roof and failure depth of the floor are $25 \mathrm{~m}$ and $28 \mathrm{~m}$, respectively. The failure depth of the floor is identical to the maximum failure depth of $23.66 \mathrm{~m}$ calculated by equation (5), and the failure depth of $7.54 \mathrm{~m}$ at a certain point near the $1118_{1} 3$ haulage roadway with an angle of $\alpha=30^{\circ}$ is also basically the same. As shown in Figures 4(c) and 4(d), when the 11175 mining face is mined out and the excavation of the $1118_{1} 3$ haulage roadway continues, the failure of the roof and floor shows obvious zoning characteristics, that is, tensile shear failure Zone A, shear slip Zone B-1, shear slip Zone B-2, and critical tensile shear failure Zone $C$. The height of the tensile shear failure zone reaches $10 \mathrm{~m}$ to $11 \mathrm{~m}$, the failure height of the shear slip Zone B-1 ranges from $90 \mathrm{~m}$ to $91 \mathrm{~m}$, and the failure depth of the shear slip Zone B-2 is stable, approximately $28 \mathrm{~m}$. After excavation of the $1118_{1} 3$ haulage roadway, extensive tensile shear failure occurred in Zone C, which was originally in the critical state of the shear slip Zone B-2.
According to the vertical stress distribution characteristics in the different stages of mining and excavation in Figure 5, as shown in Figure 5(a), when the 11173 haulage roadway and 11175 return-air roadway of the upper coal seam are excavated completely, stress concentration occurs on both sides of the mining roadway. The maximum stress of the solid coal side is approximately $8 \mathrm{MPa}$, and the stress concentration coefficient is 1.4. The maximum stress of the coal pillar side is approximately $9.1 \mathrm{MPa}$, and the stress concentration coefficient is approximately 1.5. As shown in Figure 5(b), when the 11173 mining face is mined out, the maximum stress on the side of the 11173 mining face and the solid coal side of the 11175 return-air roadway is $16 \mathrm{MPa}$, and the stress concentration coefficient is 2.7 , while the maximum stress on the side of the coal pillar is nearly $18 \mathrm{MPa}$, and the stress concentration coefficient is 3 . As shown in Figure 5(c), when the 11175 mining face is mined out, the maximum stress of the 11173 mining face side and 11175 return-air roadway solid coal side reaches $19 \mathrm{MPa}$, and the stress concentration coefficient reaches 3.2; when the maximum stress of the coal pillar side is nearly $21 \mathrm{MPa}$, the stress concentration coefficient reaches 3.5. As shown in Figure 5(d), after the excavation of the $1118_{1} 3$ haulage roadway, the maximum stress on the mining face side of the 11173 mining face and the solid coal side of the 11175 return air roadway is nearly $19 \mathrm{MPa}$, and the stress concentration factor is 3.2. Compared with the mining process of the previous stage, the maximum stress and stress concentration coefficient on both sides are unchanged, while the maximum stress on the side of the coal pillar is nearly $14.7 \mathrm{MPa}$ and the stress concentration coefficient is 2.45; thus, the maximum stress decreases by nearly $43 \%$, and the stress concentration coefficient decreases by nearly $23 \%$.

To directly express the vertical stress distribution caused by mining disturbance, it is proposed that the "stress relief degree" of the mining space is qualitatively expressed in different zones, that is, the high-pressure relief zone (Zone A) where the stress is concentrated, the moderate pressure relief zone (Zone B-1 and Zone B-2) where the stress is moderately concentrated, and the general pressure relief zone (Zone C) where the induced stress is low. First, 


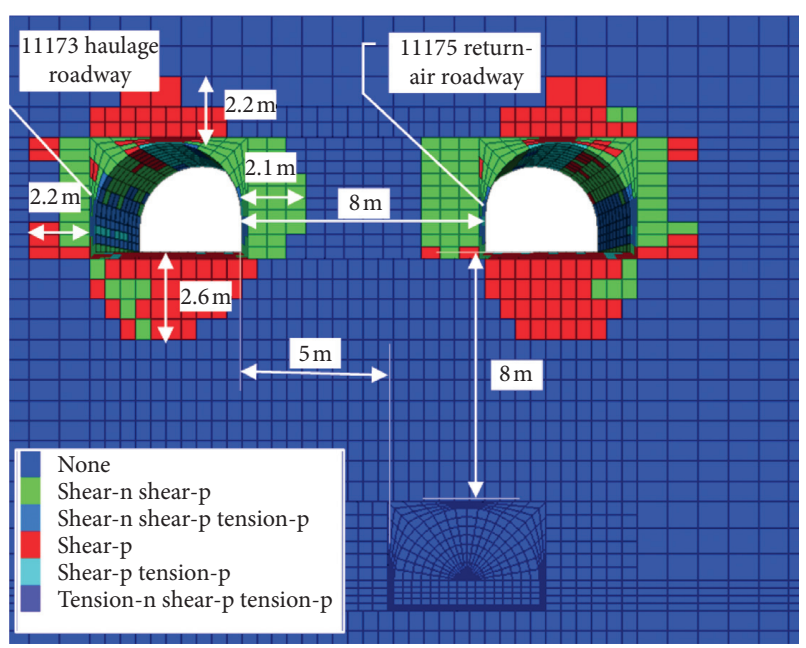

(a)

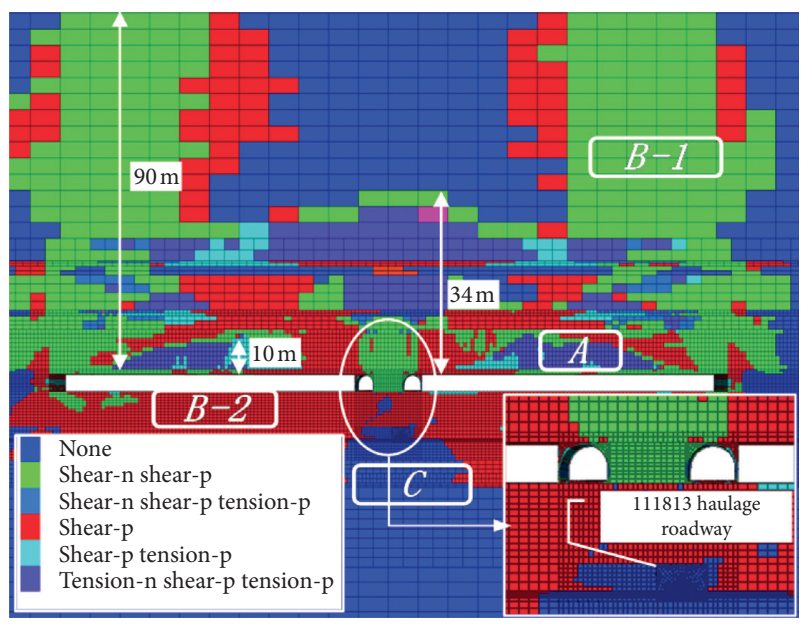

(c)

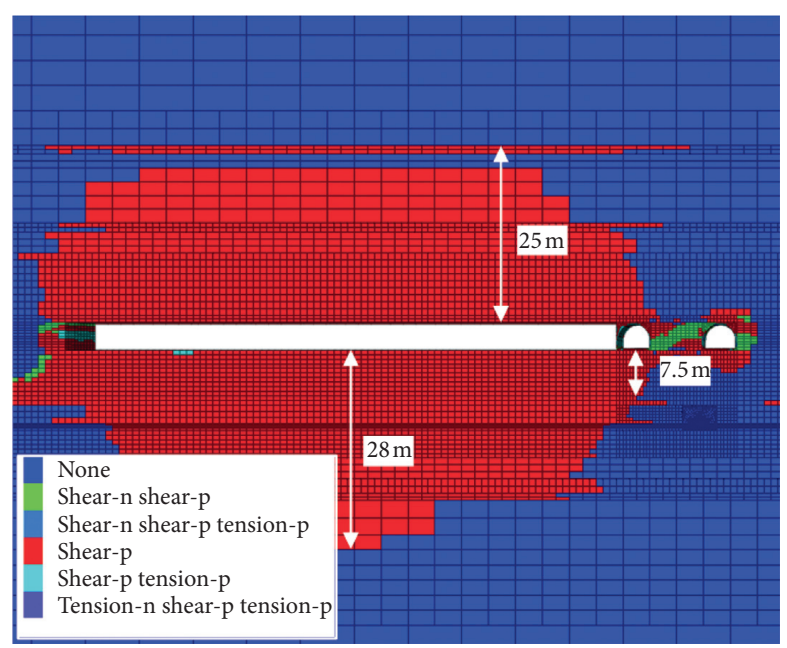

(b)

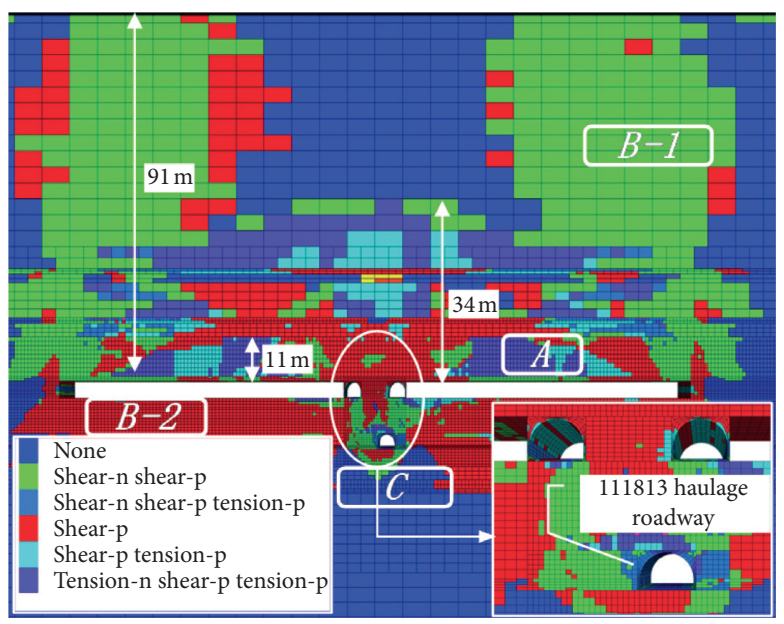

(d)

FIGURE 4: Distribution of the plastic zone of the surrounding rock in different stages of mining and excavation. (a) The mining roadway is excavated. (b) The 11173 mining face is mined out. (c) The 11173 mining face is mined out. (d) The $1118_{1} 3$ haulage roadway is excavated.

comparing the plastic zone of the surrounding rock in Figure 4(b) with the distribution of the "stress relief degree" in Figure 5(b), when the 11173 mining face is mined out and the stress balance is computed, the height of the "stress relief degree" zones in the upper coal seam is approximately $28 \mathrm{~m}$, and the depth of the "stress relief degree" zones in the lower coal seam (slightly lower than the upper coal seam "stress relief degree") is approximately $29 \mathrm{~m}$, which is identical with the failure height of the overlying strata $(25 \mathrm{~m})$ or the failure depth of the floor strata $(28 \mathrm{~m})$ in Figure $4(\mathrm{~b})$. Second, Figures 5(c) and 5(d) show that when the 11175 mining face has been mined out and the $1118_{1} 3$ haulage roadway is being excavated, the height of high-pressure relief zone (Zone A) ranges from $12 \mathrm{~m}$ to $13 \mathrm{~m}$, and that of the moderate pressure relief zone (Zone B-1) ranges from $85 \mathrm{~m}$ to $88 \mathrm{~m}$. Compared with the results in Figures 4(c) and 4(d), the heights of the tensile shear failure zone (Zone A) and shear slip zone (Zone B-2) $(10 \mathrm{~m}$ to $11 \mathrm{~m}$ and $90 \mathrm{~m}$ to $91 \mathrm{~m}$, respectively) (Figures 5(c) and 5(d)) are the same, and the plastic failure depth is nearly stable. Finally, Figures 5(c) and 5(d) show that the depth of the surrounding rock of the same order of magnitude in Zone B-2 does not change because it does not reach its ultimate failure strength. When the $1118_{1} 3$ haulage roadway is excavated, the "stress relief degree" of the general pressure relief zone (Zone $\mathrm{C}$ ) increases again due to change from the critical state of the previous stage, and the surrounding rock stress is transferred sharply to the mining space.

From the above analysis of Figures 4 and 5, the $1118_{1} 3$ haulage roadway is arranged in the lower coal seam under the coal pillar. In principle, it is located in the stress release area. Furthermore, according to equation (5), the failure depth of a certain point along this roadway is $7.54 \mathrm{~m}$, and the $1118_{1} 3$ haulage roadway does not undergo plastic failure caused by mining. However, compared with Figures 5(c) and 5 (d), after the excavation of the $1118_{1} 3$ haulage roadway, the maximum stress and stress concentration coefficient on both sides remain nearly unchanged, while the maximum stress at the side of the coal pillar decreases to $14.7 \mathrm{MPa}$, and the stress concentration coefficient decreases to 2.45. Therefore, plastic failure and compaction occur; the elastic core of the coal pillar completely loses its load capacity, and the load 


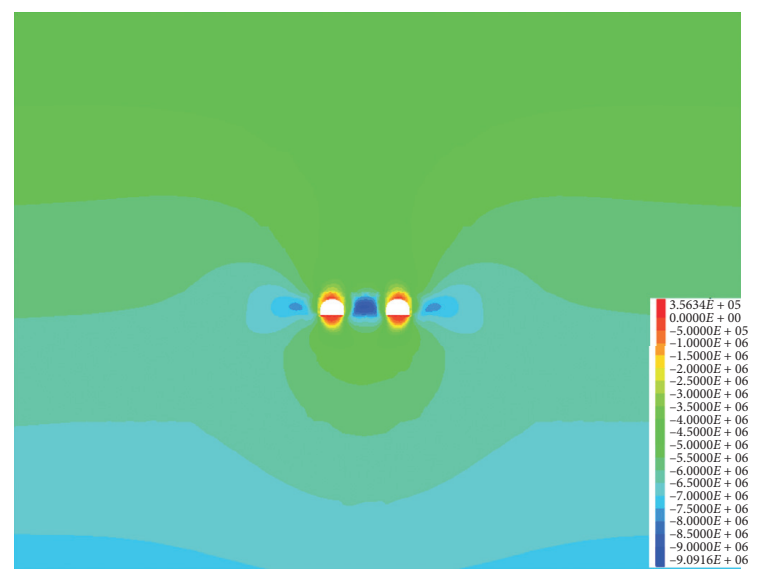

(a)

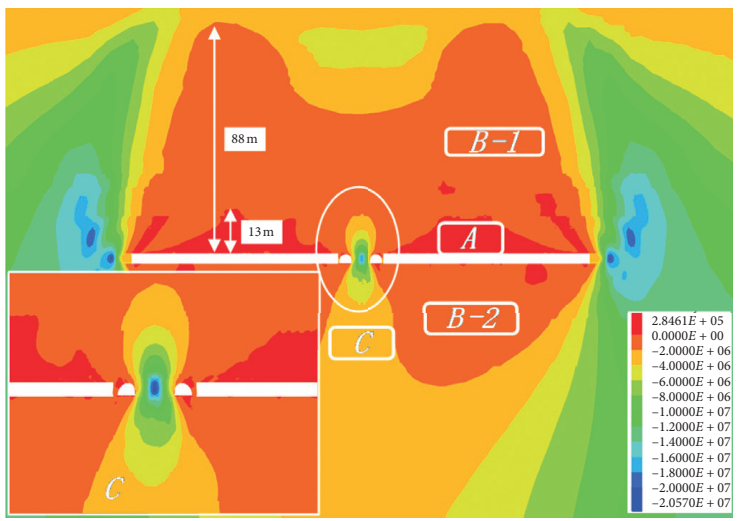

(c)

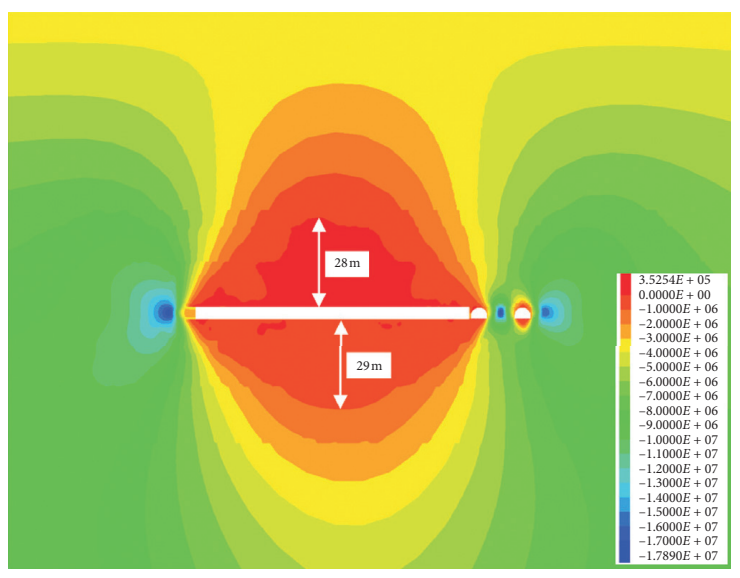

(b)

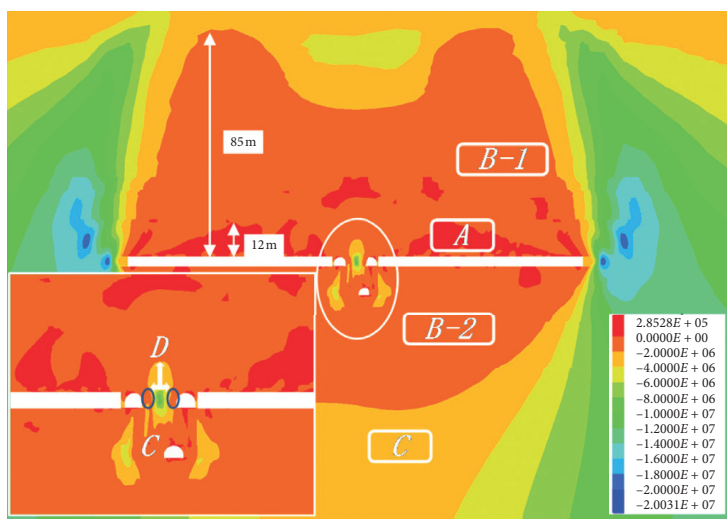

(d)

FIGURE 5: Vertical stress distribution of the surrounding rock in different stages of mining and excavation. (a) The mining roadway is excavated. (b) The 11173 mining face is mined out. (c) The 11173 mining face is mined out. (d) The $1118_{1} 3$ haulage roadway is excavated.

generated by the surrounding rock transfers rapidly to the mining space, which will cause the surrounding rock of the roadway to deform violently.

\section{Analysis of the Stress and Energy Evolution}

3.1. Theoretical Analysis of the Coal Pillar Load in the Goaf. With the advance of the mining face, the exposed area of the goaf increases gradually. When the mining face advances to the limit caving span, the roof will separate and fracture and ultimately fill the goaf. However, the load of the overlying unbroken rock will be transferred to the solid coal or the coal pillar by the equivalent cantilever beam or plate. Qian et al. [18], Li [20], and Liu [21] suggested that the load on the coal pillar mainly comes from the weight of the overlying strata above the goaf. This part of the weight is the superposition of the overburden weight on one or both sides of the goaf, as shown in Figure 6.

In such cases, Qian et al. [18] suggested that a plane problem is considered instead of a spatial problem and that homogeneous overlying rock is assumed instead of the complex rock. Without considering the stress concentration at the edge of the coal pillar, the total load $p$ on the coal pillar can be calculated by equation (6), and the average stress per

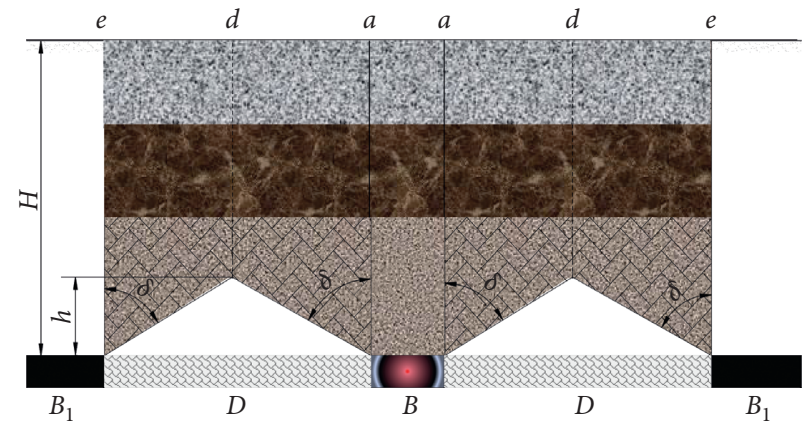

FIgURE 6: Diagram of coal pillar load calculation.

unit length of the coal pillar can be expressed by equation (7):

$$
\begin{aligned}
& p=\left[(B+D) H-\frac{D^{2} \cot \delta}{4}\right] \gamma, \\
& \sigma=\frac{p}{B}=\frac{\left[(B+D) H-\left(D^{2} \cot \delta / 4\right)\right] \gamma}{B} .
\end{aligned}
$$

Li [20] suggested that if the coal seam on one side of the coal pillar is mined out and the relationship of the goaf width 
$D$ and the mining depth $H$ meets $H>D \cdot \operatorname{ctg} \delta / 2$, the total load on the coal pillar can be expressed by equation (8), and the average stress per unit length can be expressed by equation (9):

$$
\begin{aligned}
& p=K_{1}\left[(B+D) H-\frac{D^{2} \cot \delta}{8}\right] \gamma, \\
& \sigma=K_{1} \frac{\left[(B+D) H-\left(D^{2} \cot \delta / 8\right)\right] \gamma}{B} .
\end{aligned}
$$

If the coal seams on both sides of the coal pillar are mined out and the relationship of the goaf width $D$ and the mining depth $H$ meets $H>D \cdot \operatorname{ctg} \delta / 2$, the total load on the coal pillar can be expressed by equation (10), and the average stress per unit length of the coal pillar can be expressed by equation (11):

$$
\begin{aligned}
& p=K_{1}\left[(B+D) H-\frac{D^{2} \cot \delta}{4}\right] \gamma, \\
& \sigma=K_{1} \frac{\left[(B+D) H-\left(D^{2} \cot \delta / 4\right)\right] \gamma}{B} .
\end{aligned}
$$

Liu [21] suggested that if the coal seam on one side of the coal pillar is mined out, the total load on the coal pillar can be expressed by equation (12), and the average stress per unit length of the coal pillar can be expressed by equation (13):

$$
\begin{aligned}
& p=\left[\left(\frac{B+D}{2}\right) H-\frac{(D-h \tan \delta) h}{2}\right] \gamma, \\
& \sigma=\frac{[((B+D) / 2) H-((D-h \tan \delta) h / 2)] \gamma}{B} .
\end{aligned}
$$

If the coal seams on both sides of the coal pillar are mined out, the total load on the coal pillar can be expressed by equation (14), and the average stress per unit length of the coal pillar can be expressed by equation (15):

$$
\begin{aligned}
& p=[(B+D) H-(D-h \tan \delta) h] \gamma, \\
& \sigma=\frac{[(B+D) H-(D-h \tan \delta) h] \gamma}{B},
\end{aligned}
$$

where $p$ is the total load on the coal pillar; $\sigma$ is the average stress; $K_{1}$ is the load coefficient; $B$ is the width of the coal pillar; $D$ is the width of the goaf; $H$ is the burial depth of the roadway; $\delta$ is caving angle of the overburden rock in the empty area; and $\gamma$ is the density of the overburden rock.

The area analysis method, which only considers the stress field due to the weight of the overlying rock, is used to calculate the load [22]. When the mining width is small, the basic roof generally does not cave except for the false roof and direct roof in the goaf, and the load above the mining width is borne by the coal pillar. Then, the load $p$ of the coal pillar can be calculated by equation (16); when the mining width of one side of the coal pillar is larger, more caving gangue forms, and the displacement of the roof and floor is so large that the roof is in contact with the caving gangue.
When the goaf is $0.3 \mathrm{H}$ from the coal pillar side, the load on a unit length of the gangue in the goaf is $\gamma H$ and linearly distributed along the mining depth, and the load on the coal pillar can be calculated by equation (17):

$$
\begin{aligned}
p & =(a+b) \gamma H, \\
p^{\prime} & =(a+b) \gamma H-\frac{\gamma b^{2}}{1.2} .
\end{aligned}
$$

In summary, many scholars do not agree on the calculation method of the load on the coal pillar. Considering the reference $\mathrm{Hu}$ [22], when the goaf is $0.3 \mathrm{H}$ from the coal pillar, the load on a unit length of the gangue in the goaf is $\gamma H^{\prime \prime}$, showing that the load on the coal pillar includes not only the overburden weight of the upper coal pillar but also the overburden weight of a certain distance from the edge of the coal pillar toward the goaf. Therefore, based on the above theory or formulas, the load of the coal pillar in the process of coal mining includes the load of the overlying rock above the coal pillar and the overlying rock within a certain distance from the edge of the coal pillar toward the goaf. After optimization, the load calculation of the coal pillar is shown in Figure 7, and the load formula of the coal pillar is derived as follows.

If the coal seam on one side of the coal pillar is mined out, the coal pillar load can be expressed by equation (18), and the average stress per unit length of the coal pillar can be expressed by equation (19):

$$
\begin{aligned}
& p=K_{1}\left[\left(\frac{B+k D}{2}\right) H-\frac{k^{2} h D}{4}\right] \gamma, \\
& \sigma=\frac{K_{1}\left[((B+k D) / 2) H-\left(k^{2} h D / 4\right)\right] \gamma}{B} .
\end{aligned}
$$

If the coal seams on both sides of the coal pillar are mined out, the coal pillar load can be expressed by equation (20), the average stress per unit length of the coal pillar can be expressed by equation (21), and the geometric relationship between $h$ and $D$ is expressed by equation (22):

$$
\begin{aligned}
p & =K_{1}\left[(B+k D) H-\frac{k^{2} h D}{2}\right] \gamma, \\
\sigma & =\frac{K_{1}\left[(B+k D) H-\left(k^{2} h D / 2\right)\right] \gamma}{B}, \\
\frac{h}{D} & =\frac{\cot \delta}{2},
\end{aligned}
$$

where $p$ or $p^{\prime}$ is the total load on the coal pillar; $K_{1}$ is the load coefficient, which is determined by the mining condition and depth of the coal seam; $B$ is the width of the coal pillar; $k$ is the ratio of the horizontally projected distance of the weight from the side overburden rock in the goaf that the coal pillar bears to $D / 2 ; \delta$ is the caving angle of the overburden rock in the empty area; and $\gamma$ is the density of the overburden rock. 


\subsection{Analysis of Deformation Zoning and Stress Superposition}

3.2.1. One Side of the Coal Pillar Is Mined Out. Considering the work of Qian et al. [18], it is assumed that when the coal seam on one side of the coal pillar is mined out, it deforms elastically, and the vertical stress distribution of the coal pillar is shown in curve 1 in Figure 8: $\sigma_{v}$ attenuates exponentially with the increase in the distance from the edge of the goaf. As shown in curve 2 in Figure 8, under the high stress caused by mining, the elastoplastic deformation zone of the coal pillar will extend downward from the edge of the pillar; Zone I and Zone II are the fracture zone and the plastic zone, respectively, which are in the limit equilibrium state and together form the limit equilibrium zone.

With increasing distance from the edge of the goaf, the bearing capacity of the coal pillar increases gradually. Therefore, the elastic zone (Zone III), which is higher than the original rock stress, and the original rock stress zone (Zone IV), which is unmined, are formed.

3.2.2. Both Sides of the Coal Pillar Are Mined Out. When the coal seams on both sides of the small pillar are mined out and the abutment pressure disturbance distance caused by mining is greater than the width of the coal pillar, the central load of the coal pillar is sharply superimposed. At this time, the vertical stress is roughly uniformly distributed in stage $d^{\prime} d^{\prime \prime}$, and the vertical stress is curvilinearly distributed in stages $\overline{a^{\prime} d^{\prime}}$ and $\overline{a^{\prime \prime} d^{\prime \prime}}$, which result in a long-term plastic flow in Zone I (fracture zone), Zone II (plastic zone), and Zone III (elastic zone with increased stress) of the coal pillar. This leads to failure and instability of the coal pillar, as shown in Figure 9.

3.3. Floor Stress Evolution Analysis of a Semi-Infinite Body. Many scholars use the average stress to express the load of a point under a coal pillar, but this is not the case here. As shown in Figure 10, the vertical stress in $\overline{d^{\prime} d^{\prime \prime}}$ has a uniform distribution, which can be approximately simplified to a horizontal straight line. However, $\overline{a^{\prime} d^{\prime}}$ and $a^{\prime \prime} d^{\prime \prime}$ show curvilinear distributions, which can be approximately simplified as oblique lines. Therefore, the load on the coal pillar should be calculated in segments.

The uniformly distributed stress of $\overline{d^{\prime} d^{\prime \prime}}$ is simplified as shown in Figure 11, and the floor is regarded as an elastic medium. Based on elastic mechanics theory [23], a formula for the stress of a coal pillar has been proposed [24], Xu et al. [7] and Zhang et al. [9]. The stress calculation formula of a point $(x, y)$ near the roadway surrounding rock is shown in equations $(23 \mathrm{a})$ to $(25 \mathrm{c})$ :

$$
\begin{aligned}
& \sigma_{x_{1}}=\frac{K\left[(B+k D) H-\left(k^{2} h D / 2\right)\right] \gamma}{\pi B}\left[\arctan \frac{y+\left(\overline{d^{\prime} d^{\prime \prime}} / 2\right)}{x^{2}+1}-\arctan \frac{x-\left(\overline{d^{\prime} d^{\prime \prime}} / 2\right)}{y}-\frac{y\left(x+\left(\overline{d^{\prime} d^{\prime \prime}} / 2\right)\right)}{y^{2}+\left(x+\left(\overline{d^{\prime} d^{\prime \prime}} / 2\right)\right)^{2}}+\frac{y\left(x-\overline{d^{\prime} d^{\prime \prime}} / 2\right)}{y^{2}+\left(x-\overline{d^{\prime} d^{\prime \prime}} / 2\right)^{2}}\right] \\
& =\frac{K \prime \gamma H}{\pi}\left[\arctan \frac{y+\left(\overline{d^{\prime} d^{\prime \prime}} / 2\right)}{x^{2}+1}-\arctan \frac{x-\left(\overline{d^{\prime} d^{\prime \prime}} / 2\right)}{y}-\frac{y\left(x+\left(\overline{d^{\prime} d^{\prime \prime}} / 2\right)\right)}{y^{2}+\left(x+\left(\overline{d^{\prime} d^{\prime \prime}} / 2\right)\right)^{2}}+\frac{y\left(x-\left(\overline{d^{\prime} d^{\prime \prime}} / 2\right)\right)}{y^{2}+\left(x-\left(\overline{d^{\prime} d^{\prime \prime}} / 2\right)\right)^{2}}\right], \\
& \sigma_{y_{1}}=\frac{K\left[(B+k D) H-\left(k^{2} h D / 2\right)\right] \gamma}{\pi B}\left[\arctan \frac{x+\left(\overline{d^{\prime} d^{\prime \prime}} / 2\right)}{y}-\arctan \frac{x-\left(\overline{d^{\prime} d^{\prime \prime}} / 2\right)}{y}+\frac{y\left(x+\left(\overline{d^{\prime} d^{\prime \prime}} / 2\right)\right)}{y^{2}+\left(x+\left(\overline{d^{\prime} d^{\prime \prime}} / 2\right)\right)^{2}}\right. \\
& \left.-\frac{y\left(x-\left(\overline{d^{\prime} d^{\prime \prime}} / 2\right)\right)}{y^{2}+\left(x-\left(\overline{d^{\prime} d^{\prime \prime}} / 2\right)\right)^{2}}\right] \\
& =\frac{K^{\prime} \gamma H}{\pi}\left[\arctan \frac{x+\left(\overline{d^{\prime} d^{\prime \prime}} / 2\right)}{y}-\arctan \frac{x-\left(\overline{d^{\prime} d^{\prime \prime}} / 2\right)}{y}+\frac{y\left(x+\left(\overline{d^{\prime} d^{\prime \prime}} / 2\right)\right)}{y^{2}+\left(x+\left(\overline{d^{\prime} d^{\prime \prime}} / 2\right)\right)^{2}}-\frac{y\left(x-\left(\overline{d^{\prime} d^{\prime \prime}} / 2\right)\right)}{y^{2}+\left(x-\left(\overline{d^{\prime} d^{\prime \prime}} / 2\right)\right)^{2}}\right] \text {, } \\
& \tau_{x y_{1}}=-\frac{K\left[(B+k D) H-\left(k^{2} h D / 2\right)\right] \gamma}{\pi B}\left[\frac{y^{2}}{y^{2}+\left(x+\left(\overline{d^{\prime} d^{\prime \prime}} / 2\right)\right)^{2}}-\frac{y^{2}}{y^{2}+\left(x-\left(\overline{d^{\prime} d^{\prime \prime}} / 2\right)\right)^{2}}\right] \\
& =-\frac{K^{\prime} \gamma H}{\pi}\left[\frac{y^{2}}{y^{2}+\left(x+\left(\overline{d^{\prime} d^{\prime \prime}} / 2\right)\right)^{2}}-\frac{y^{2}}{y^{2}+\left(x-\left(\overline{d^{\prime} d^{\prime \prime}} / 2\right)\right)^{2}}\right] \text {, }
\end{aligned}
$$


where $K=K_{0} K_{1}$, in which $K_{0}$ is a multiple of the average stress and $K^{\prime}$ is the stress concentration coefficient.

According to the theory of elastic mechanics [23], linear segments $\overline{a^{\prime} d^{\prime}}$ and $\overline{a^{\prime \prime} d^{\prime \prime}}$ are simplified as shown in Figure 12, and the stress components caused by the small concentrated forces $q^{\prime} d \xi$ and $q^{\prime \prime} d \xi^{\prime}$ at a point $(x, y)$ in the semi-infinite body are given in equations $(24 \mathrm{a})$ to $(25 \mathrm{c})$ :

$$
\overline{a^{\prime} d^{\prime}}
$$

$$
\begin{aligned}
& \sigma_{x_{2}}=\frac{2}{\pi} \int_{-x_{a}}^{-x_{d}} \frac{(x-\xi)^{2} y q^{\prime}(\xi) \mathrm{d} \xi}{\left[(x-\xi)^{2}+y^{2}\right]^{2}}=\frac{2 \gamma H}{\pi} \int_{-x_{a}^{\prime}}^{-x_{d}} \frac{\left[\left(\xi+x_{b^{\prime}}\right)\left(1-K^{\prime}\right)+\left(x_{d^{\prime}}-x_{a^{\prime}}\right)\right](x-\xi)^{2} y \mathrm{~d} \xi}{\left[(x-\xi)^{2}+y^{2}\right]^{2}\left[x_{d^{\prime}}-x_{a^{\prime}}\right]}, \\
& \sigma_{y_{2}}=\frac{2}{\pi} \int_{-x_{a}^{\prime}}^{-x_{d}} \frac{y^{3} q^{\prime}(\xi) \mathrm{d} \xi}{\left[(x-\xi)^{2}+y^{2}\right]^{2}}=\frac{2 \gamma H}{\pi} \int_{-x_{a}}^{-x_{d}^{\prime}} \frac{\left[\left(\xi+x_{b^{\prime}}\right)\left(1-K^{\prime}\right)+\left(x_{d^{\prime}}-x_{a^{\prime}}\right)\right] y^{3} \mathrm{~d} \xi}{\left[(x-\xi)^{2}+y^{2}\right]^{2}\left[x_{d^{\prime}}-x_{a^{\prime}}\right]}, \\
& \tau_{x y_{2}}=\frac{2}{\pi} \int_{-x_{a}}^{-x_{d}} \frac{(x-\xi) y^{2} q^{\prime}(\xi) \mathrm{d} \xi}{\left[(x-\xi)^{2}+y^{2}\right]^{2}}=\frac{2 \gamma H}{\pi} \int_{-x_{a}^{\prime}}^{-x_{d}} \frac{\left[\left(\xi+x_{b^{\prime}}\right)\left(1-K^{\prime}\right)+\left(x_{d^{\prime}}-x_{a^{\prime}}\right)\right](x-\xi) y^{2} \mathrm{~d} \xi}{\left[(x-\xi)^{2}+y^{2}\right]^{2}\left[x_{d^{\prime}}-x_{a^{\prime}}\right]} .
\end{aligned}
$$

$\overline{a^{\prime \prime} d^{\prime \prime}}$

$$
\begin{aligned}
& \sigma_{x_{3}}=\frac{2}{\pi} \int_{x_{d}^{\prime \prime}}^{x_{a}^{\prime \prime}} \frac{\left(x+\xi^{\prime}\right)^{2} y q \prime \prime}{\left[\left(\xi+\xi^{\prime}\right)^{2}+y^{2}\right]^{2}}=\frac{2 \gamma H}{\pi} \int_{x_{d}^{\prime \prime}}^{x_{a}^{\prime \prime}} \frac{\left[\left(K^{\prime}-1\right)\left(\xi^{\prime}-x_{b^{\prime \prime}}\right)+\left(x_{d^{\prime \prime}}-x_{b^{\prime \prime}}\right)\right]\left(x+\xi^{\prime}\right)^{2} y \mathrm{~d} \xi^{\prime}}{\left[\left(x+\xi^{\prime}\right)^{2}+y^{2}\right]^{2}\left[x_{d^{\prime \prime}}-x_{b^{\prime \prime}}\right]}, \\
& \sigma_{y_{3}}=\frac{2}{\pi} \int_{x_{d}^{\prime \prime}}^{x_{a}^{\prime \prime}} \frac{y^{3} q^{\prime \prime}(\xi) \mathrm{d} \xi^{\prime}}{\left[\left(x+\xi^{\prime}\right)^{2}+y^{2}\right]^{2}}=\frac{2 \gamma H}{\pi} \int_{x_{d}^{\prime \prime}}^{x_{a}^{\prime \prime}} \frac{\left[\left(K^{\prime}-1\right)\left(\xi^{\prime}-x_{b^{\prime \prime}}\right)+\left(x_{d^{\prime \prime}}-x_{b^{\prime \prime}}\right)\right] y^{3} \mathrm{~d} \xi^{\prime}}{\left[\left(x+\xi^{\prime}\right)^{2}+y^{2}\right]^{2}\left[x_{d^{\prime \prime}}-x_{b^{\prime \prime}}\right]}, \\
& \tau_{x y_{3}}=\frac{2}{\pi} \int_{x_{d}^{\prime \prime}}^{x_{a}^{\prime \prime}} \frac{\left(x+\xi^{\prime}\right) y^{2} q^{\prime \prime}(\xi) \mathrm{d} \xi^{\prime}}{\left[\left(x+\xi^{\prime}\right)^{2}+y^{2}\right]^{2}}=\frac{2 \gamma H}{\pi} \int_{x_{d}^{\prime \prime}}^{x_{a}^{\prime \prime}} \frac{\left[\left(K^{\prime}-1\right)\left(\xi^{\prime}-x_{b^{\prime \prime}}\right)+\left(x_{d^{\prime \prime}}-x_{b^{\prime \prime}}\right)\right]\left(x+\xi^{\prime}\right) y^{2} \mathrm{~d} \xi^{\prime}}{\left[\left(x+\xi^{\prime}\right)^{2}+y^{2}\right]^{2}\left[x_{d^{\prime \prime}}-x_{b^{\prime \prime}}\right]} .
\end{aligned}
$$

3.4. Analysis of Energy Accumulation and Release. It is assumed that a coal and rock mass is in a dynamic equilibrium state and under the same temperature condition as that at the surface. According to Zhang [24], when a coal and rock mass is subjected to mining activities or geological actions, the elastic strain energy and other energy accumulated in coal and rock are released instantaneously. Therefore, a representative mathematical expression is as follows:

$$
U_{0}=F\left(U_{a}+U_{b}+U_{c}+U_{d}+U_{e}+U_{f}\right),
$$

where $U_{0}$ is a function of different dissipated energies; $U_{a}$ is the elastic strain energy produced in the process of rock stability; $U_{b}$ is the surface energy generated by the new surface; $U_{c}$ is the kinetic energy; $U_{d}$ is the radiant energy in the process of stability; $U_{e}$ is the energy consumed by the biological activities in the coal and rock mass; and $U_{f}$ is the undiscovered energy consumption.

According to Section 3.3, the stress component under the coal pillar can be obtained by the superposition of the stress components around the floor roadway [25]. Therefore, 
the expression of the stress component at point $(x, y)$ is as follows:

$$
\begin{aligned}
& \sigma_{x}=\sigma_{x_{1}}+\sigma_{x_{2}}+\sigma_{x_{3}}=\frac{K\left[(B+k D) H-\left(k^{2} h D / 2\right)\right] \gamma}{\pi B}\left[\arctan \frac{y+\left(\overline{d^{\prime} d^{\prime \prime}} / 2\right)}{x^{2}+1}-\arctan \frac{x-\left(\overline{d^{\prime} d^{\prime \prime}} / 2\right)}{y}\right. \\
& \left.-\frac{y\left(x+\left(\overline{d^{\prime} d^{\prime \prime}} / 2\right)\right)}{y^{2}+\left(x+\left(\overline{d^{\prime} d^{\prime \prime}} / 2\right)\right)^{2}}+\frac{y\left(x-\left(\overline{d^{\prime} d^{\prime \prime}} / 2\right)\right)}{y^{2}+\left(x-\left(\overline{d^{\prime} d^{\prime \prime}} / 2\right)\right)^{2}}\right] \\
& +\frac{2 \gamma H}{\pi} \int_{-x_{a^{\prime}}}^{-x_{d^{\prime}}} \frac{\left[\left(\xi+x_{b^{\prime}}\right)\left(1-K^{\prime}\right)+\left(x_{d^{\prime}}-x_{a^{\prime}}\right)\right](x-\xi)^{2} y \mathrm{~d} \xi}{\left[(x-\xi)^{2}+y^{2}\right]^{2}\left[x_{d^{\prime}}-x_{a^{\prime}}\right]}+\frac{2 \gamma H}{\pi} \int_{x_{d}^{\prime \prime}}^{x_{a}^{\prime \prime}} \frac{\left[\left(K^{\prime}-1\right)\left(\xi^{\prime}-x_{b^{\prime \prime}}\right)+\left(x_{d^{\prime \prime}}-x_{b^{\prime \prime}}\right)\right]\left(x+\xi^{\prime}\right)^{2} y \mathrm{~d} \xi^{\prime}}{\left[\left(x+\xi^{\prime}\right)^{2}+y^{2}\right]^{2}\left[x_{d^{\prime \prime}}-x_{b^{\prime \prime}}\right]}, \\
& \sigma_{y}=\sigma_{y_{1}}+\sigma_{y_{2}}+\sigma_{y_{3}}=\frac{K\left[(B+k D) H-\left(k^{2} h D / 2\right)\right] \gamma}{\pi B}\left[\arctan \frac{x+\left(\overline{d^{\prime} d^{\prime \prime}} / 2\right)}{y}-\arctan \frac{x-\left(\overline{d^{\prime} d^{\prime \prime}} / 2\right)}{y}\right. \\
& \left.+\frac{y\left(x+\left(\overline{d^{\prime} d^{\prime \prime}} / 2\right)\right)}{y^{2}+\left(x+\left(\overline{d^{\prime} d^{\prime \prime}} / 2\right)\right)^{2}}-\frac{y\left(x-\left(\overline{d^{\prime} d^{\prime \prime}} / 2\right)\right)}{y^{2}+\left(x-\left(\overline{d^{\prime} d^{\prime \prime}} / 2\right)\right)^{2}}\right] \\
& +\frac{2 \gamma H}{\pi} \int_{-x_{a^{\prime}}}^{-x_{d^{\prime}}} \frac{\left[\left(\xi+x_{b^{\prime}}\right)\left(1-K^{\prime}\right)+\left(x_{d^{\prime}}-x_{a^{\prime}}\right)\right] y^{3} \mathrm{~d} \xi}{\left[(x-\xi)^{2}+y^{2}\right]^{2}\left[x_{d^{\prime}}-x_{a^{\prime}}\right]}+\frac{2 \gamma H}{\pi} \int_{x_{d}^{\prime \prime}}^{x_{a}^{\prime \prime}} \frac{\left[\left(K^{\prime}-1\right)\left(\xi^{\prime} x_{b^{\prime \prime}}\right)+\left(x_{d^{\prime \prime}}-x_{b^{\prime \prime}}\right)\right] y^{3} \mathrm{~d} \xi^{\prime}}{\left[\left(x+\xi^{\prime}\right)^{2}+y^{2}\right]^{2}\left[x_{d^{\prime \prime}}-x_{b^{\prime \prime}}\right]}, \\
& \tau_{x y}=\tau_{x y_{1}}+\tau_{x y_{2}}+\tau_{x y_{3}}=-\frac{K\left[(B+k D) H-\left(k^{2} h D / 2\right)\right] \gamma}{\pi B}\left[\frac{y^{2}}{y^{2}+\left(x+\left(\overline{d^{\prime} d^{\prime \prime}} / 2\right)\right)^{2}}-\frac{y^{2}}{y^{2}+\left(x-\left(\overline{d^{\prime} d^{\prime \prime}} / 2\right)\right)^{2}}\right] \\
& +\frac{2 \gamma H}{\pi} \int_{-x_{a^{\prime}}}^{-x_{d^{\prime}}} \frac{\left[\left(\xi+x_{b^{\prime}}\right)\left(1-K^{\prime}\right)+\left(x_{d^{\prime}}-x_{a^{\prime}}\right)\right](x-\xi) y^{2} \mathrm{~d} \xi}{\left[(x-\xi)^{2}+y^{2}\right]^{2}\left[x_{d^{\prime}}-x_{a^{\prime}}\right]}+\frac{2 \gamma H}{\pi} \int_{x_{d}^{\prime \prime}}^{x_{a}^{\prime \prime}} \frac{\left[\left(K^{\prime}-1\right)\left(\xi^{\prime}-x_{b^{\prime \prime}}\right)+\left(x_{d^{\prime \prime}}-x_{b^{\prime \prime}}\right)\right]\left(x+\xi^{\prime}\right) y^{2} \mathrm{~d} \xi^{\prime}}{\left[\left(x+\xi^{\prime}\right)^{2}+y^{2}\right]^{2}\left[x_{d^{\prime \prime}}-x_{b^{\prime \prime}}\right]}
\end{aligned}
$$

The roadway surrounding rock that does not undergo plastic failure under the coal pillar is assumed to be a homogeneous and continuously elastic body. According to Hooke's law, the strain component of the surrounding rock at a point around the floor roadway can be obtained as follows:

$$
\begin{aligned}
\varepsilon_{x} & =\frac{1-\mu^{2}}{E}\left(\sigma_{x}-\frac{\mu}{1-\mu} \sigma_{y}\right), \\
\varepsilon_{y} & =\frac{1-\mu^{2}}{E}\left(\sigma_{y}-\frac{\mu}{1-\mu} \sigma_{x}\right), \\
\gamma_{x y} & =\frac{2(1+\mu)}{E} \tau_{x y} .
\end{aligned}
$$

In addition, the release of energy in a coal and rock mass causes internal damage and deformation of the coal and rock $[13,24]$, and the release of elastic strain energy is the main reason for the failure of coal and rock masses. Therefore, only the elastic strain energy produced by the coal and rock mass is considered in this paper. According to elastic mechanics [23] and equations (27a) to (28c), the expression of elastic strain energy produced by a coal and rock mass at a point around the floor roadway is as follows:

$$
\begin{aligned}
U_{a}= & \frac{E}{2\left(1-u^{2}\right)}\left(\varepsilon_{x}^{2}+\varepsilon_{y}^{2}+2 \mu \varepsilon_{x} \varepsilon_{y}+\frac{1-u}{2} \gamma_{x y}^{2}\right) \\
= & \frac{1}{2}\left(\left(\frac{1-\mu^{2}}{E}\left(\sigma_{x}-\frac{\mu}{1-\mu} \sigma_{y}\right)^{2}\right)+\left(\frac{1-\mu^{2}}{E}\left(\sigma_{y}-\frac{\mu}{1-\mu} \sigma_{x}\right)^{2}\right)\right. \\
& \left.+2 \mu\left(\frac{1-\mu^{2}}{E}\right)\left(\sigma_{x}-\frac{\mu}{1-\mu} \sigma_{y}\right)\left(\sigma_{y}-\frac{\mu}{1-\mu} \sigma_{x}\right)+\frac{2}{E}(1+\mu) \tau_{x y}^{2}\right),
\end{aligned}
$$

where $E$ and $u$ are the elastic modulus and Poisson's ratio, respectively.

In plane problems, the stress and deformation components are functions of coordinates $x$ and $y$. Therefore, $U_{a}$ is 


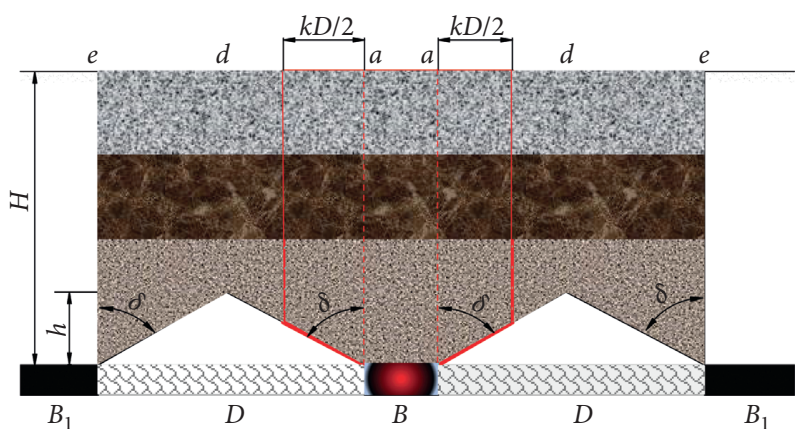

FIGURE 7: Diagram of the load on the coal pillar after optimization.

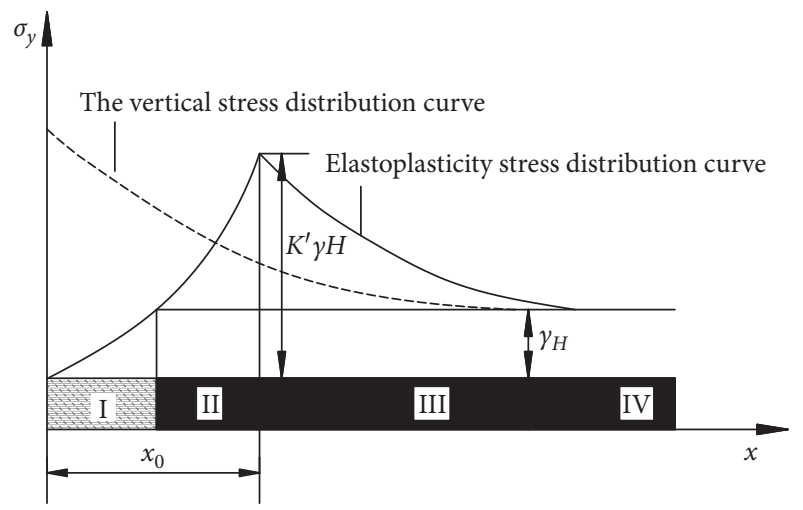

Figure 8: One side of the coal pillar is mined out.

also a function of coordinates $x$ and $y$. To more specifically express the stored strain energy of the elastic body, it is

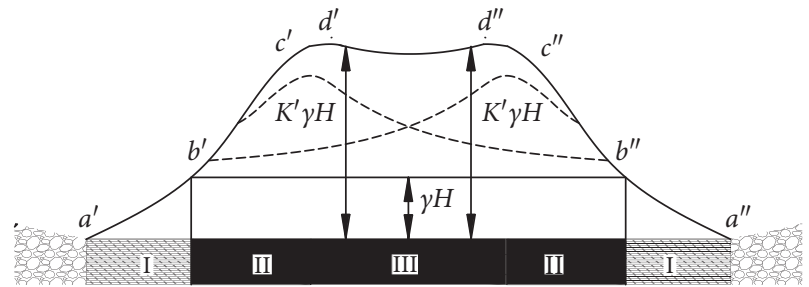

Figure 9: Both sides of the coal pillar are mined out.

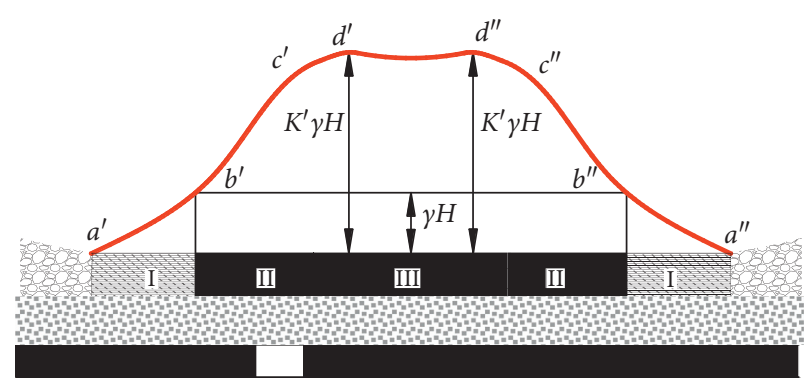

Figure 10: Diagram of the nonuniform stress distribution on the coal pillar.

necessary to integrate $U_{a}$ within a certain range (taking the $Z$ direction as the unit length):

$$
U=\iint U_{a}=\frac{1}{2} \iint\left(\left(\frac{1-\mu^{2}}{E}\left(\sigma_{x}-\frac{\mu}{1-\mu} \sigma_{y}\right)^{2}\right)+\left(\frac{1-\mu^{2}}{E}\left(\sigma_{y}-\frac{\mu}{1-\mu} \sigma_{x}\right)^{2}\right)+2 \mu\left(\frac{1-\mu^{2}}{E}\right)\left(\sigma_{x}-\frac{\mu}{1-\mu} \sigma_{y}\right)\left(\sigma_{y}-\frac{\mu}{1-\mu} \sigma_{x}\right)+\frac{2}{E}(1+\mu) \tau_{x y}^{2}\right) \mathrm{d} x \mathrm{~d} y .
$$

Equations (29) and (30) can be combined with equations (27a) to (28c) to show that the elastic strain energy of the surrounding rock of a roadway is related to not only the physical parameters (i.e., $E, u$, and $\gamma$ ) of the coal and rock mass but also the stress. Moreover, the stress and its component are closely related to the distance between the coal pillar and the surrounding rock at a certain point, the caving height and shape, the burial depth, and the width of the coal pillar (including the width of its limit equilibrium zone and the positions and $x_{d^{\prime}}$ and $\left.x_{d^{\prime \prime}}\right)$. Therefore, to provide scientific decision-making and theoretical guidance to maintain the stability of lower mining roadways, based on the above analysis, simple control factors such as the coal pillar width and roadway layout can be investigated to determine the optimal position of the roadway.

\section{Size of the Coal Pillar and Location of the Roadway}

4.1. Reasonable Coal Pillar Size. Yu et al. [26] noted that when the abutment pressure on the coal pillar exceeds the ultimate strength of the coal body, the coal body is in a state of failure, and the vertical stress is reduced below the initial rock stress, as shown by $D$ in Figure 5(d) and Zone I in Figures 9 and 10. An expression of the limit equilibrium zone is as follows:

$$
\begin{aligned}
& x_{0}=\frac{1}{2 \sqrt{\beta}} \ln \frac{2\left(c+K^{\prime} \gamma H \tan \varphi^{\prime}\right)+P \sqrt{\beta}}{2\left(c+K^{\prime} \gamma H \tan \varphi^{\prime}\right)-P \sqrt{\beta}}, \\
& \beta=\frac{K_{S}}{m E},
\end{aligned}
$$




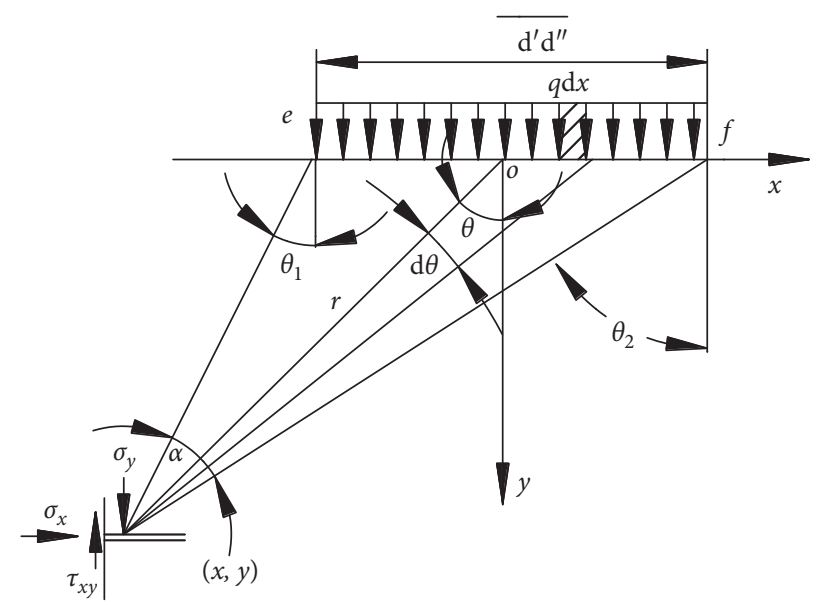

Figure 11: Diagram of a point on the floor subjected to the load $\overline{d^{\prime} d^{\prime \prime}}$.

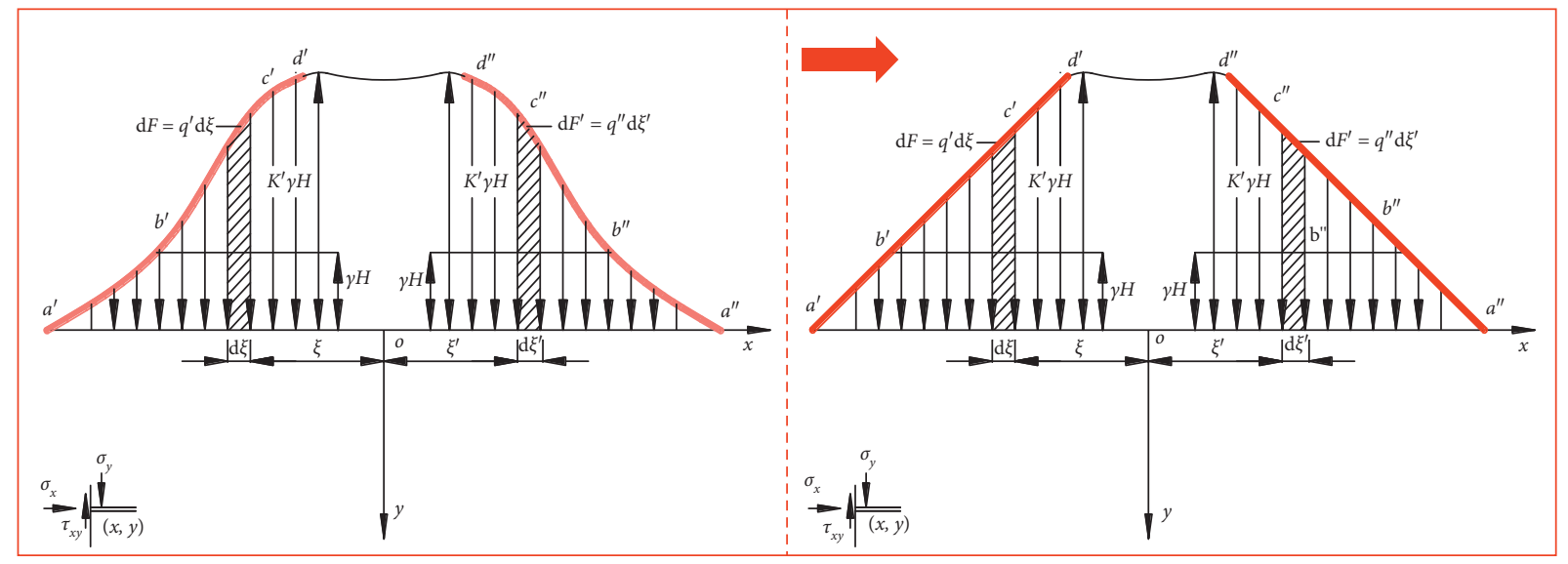

Figure 12: Diagram of the simplified stress distribution.

$$
P=P_{0}-P_{i}=m A K^{\prime} \gamma H-P_{i},
$$

where $x_{0}$ stands for the width of the limit equilibrium zone; $m$ represents the coal seam thickness, which is $4 \mathrm{~m}$ in this example; $c$ is the coal seam cohesion, which is $0.8 \mathrm{MPa} ; P_{i}$ is the resistance of the support to the coal gangue, which is $0.1 \mathrm{MPa} ; K^{\prime}$ is the stress concentration coefficient, which is 2.8; $\varphi^{\prime}$ is the friction angle of the coal seam, which is $27^{\circ} ; H$ is the burial depth of the roadway, which is $248 \mathrm{~m} ; \gamma$ is the density of the overburden rock, which is $25 \mathrm{KN} / \mathrm{m}^{3} ; E$ is the elastic modulus of the coal body, which is $2.12 \mathrm{GPa} ; K_{S}$ is the tangential stiffness of the interface between the roof and floor, which is $0.12 \mathrm{GPa} / \mathrm{m}$; and $A$ is the lateral pressure coefficient, which is 1.1 .

Substituting the above parameters into equations (31) to (33), $x_{0} \approx 4.28 \mathrm{~m}$ can be obtained. The width of the limit equilibrium zone on both sides of the coal pillar is $2 x_{0}>8 \mathrm{~m}$, which indicates that the coal pillar in the goaf undergoes plastic failure. As shown in Figure 1, if $d^{\prime}$ and $d^{\prime \prime}$ intersect or overlap, there is no elastic zone, and the effective support area of the coal pillar is insufficient. Then, the concentrated stress and accumulated elastic strain energy are released into the mining space, resulting in a large displacement of the roadway.

Therefore, according to the derivation of Qian et al. [18], it can be concluded that the minimum width of the coal pillar is as follows:

$$
B=2 x_{0}+2 m \text {. }
$$

Substituting the above parameters into equation (34), $B=16.56$ mcan be obtained. The width of the coal pillar in the goaf should be $16.56 \mathrm{~m}$, which provides a technical reference for the setting of retained coal pillars in subsequent mining.

4.2. Reasonable Roadway Location. As shown in Figure 5(c), before the excavation of the $1118_{1} 3$ haulage roadway, the rock under the coal pillar is in a state of stress balance; after the haulage roadway is excavated, the stress is redistributed, and the energy in the equilibrium state is instantly transferred to the mining space and released to reach a new dynamic balance, as shown in Figure 5(d). However, this process is inelastic and causes considerable 
surrounding rock dilatation in the mining space, which results in plastic deformation and failure of the surrounding rock. Therefore, to reduce the accumulated elastic strain energy of the surrounding rock [27], the roadway layout should be optimized to avoid the stress concentration area or energy accumulation area. According to the analysis of Section 2.4, the roadway should be arranged in shear slip Zone B-2, as shown in Figure 4(c), which is the moderate pressure relief Zone B-2 in Figure 5(c). The specific position is determined by a logarithmic spiral, which is consistent with the numerical simulation results. When $\alpha$ is approximately $26^{\circ}$ in the \#17 coal seam, a large number of weak structures form in this area due to mining, which will dissipate a part of the energy. After excavation of the $1118_{1} 3$ haulage roadway, the surrounding rock of the roadway will not have a large stress concentration and energy accumulation. However, the integrity and continuity of the surrounding rock in this area are damaged. Therefore, support structure or grouting modification [28, 29] should be adopted to maintain the stability of the surrounding rock.

\section{Conclusion and Future Prospects}

(1) The elastic strain energy accumulated in the roadway roof and upper coal pillar is related not only to the physical properties of the coal seam but also to the distance between the coal pillar and surrounding rock, the caving height and shape, the burial depth, and retained pillar width.

(2) Energy release is the main reason for the failure of coal and rock masses. Elastic strain energy accumulation in the roadway roof and upper coal pillar induces large displacements of the roadway when the energy is released during excavation.

(3) The stress distribution and failure morphology of the surrounding rock in the mining space are studied, and it is proposed that the "stress relief degree" and failure morphology are used to divide the rock into different zones. The two zoning modes have a high consistency.

(4) The stress distribution in a narrow coal pillar should be calculated by segmentation. The vertical stress in the middle segment shows a uniform distribution, which can be approximately simplified to a horizontal straight line; the limit equilibrium zones on both sides show curvilinear distributions, which can be approximately simplified as an oblique line.

(5) Based on the zoning characteristics and energy release, the following control factors, such as coal pillar width and roadway layout, are proposed: (a) for the coal pillar, avoid the overlap or intersection of the peak values in the limit equilibrium zone, and ensure a sufficient elastic area in the coal pillar; (b) arrange the roadway in shear slip Zone B-2 or the moderate pressure relief Zone B-2 to reduce the accumulated elastic strain energy in the surrounding rock.
(6) The shortcomings of this approach are as follows: (a) only the energy accumulation and release in the twodimensional state are considered; (b) the energy accumulation and release and "stress relief degree" are considered only qualitatively, not quantitatively. An in-depth study at the mesoscale $[30,31]$ will be conducted in follow-up research.

\section{Data Availability}

The related data used to support the findings of this study are included within the article and supplementary materials.

\section{Conflicts of Interest}

The authors declare that there are no conflicts of interest regarding the publication of this paper.

\section{Acknowledgments}

The authors would like to express their gratitude to the National Natural Science Foundation of China (Grant No. 51574008) and the Basic Research Program of Guizhou Province of China (Grant No. [2020]1Z047).

\section{References}

[1] L. F. Wang, Z. C. Chang, Z. B. Yang, and X. F. Wang, "Combined support technology of roadway under mined gob of ultra-distance seams in deep mine," Journal of Mining and Safety Engineering, vol. 35, no. 4, pp. 686-692, 2018.

[2] G. Y. Peng, M. Z. Gao, Y. C. Lv, and R. G. Zhang, "Investigation on mining mechanics behavior of deep close distance seam group," Journal of China Coal Society, vol. 44, no. 7, pp. 1971-1980, 2019.

[3] B. S. Zhang, S. S. Yang, L. X. Kang, and Y. D. Zhai, "Discussion on method for determining reasonable position of roadway for ultra-close multi-seam," Chinese Journal of Rock Mechanics and Engineering, vol. 27, no. 1, pp. 97-101, 2008.

[4] Y. W. Ju, G. L. Wang, and C. Hu, "Tectonic deformation and its control over thickness of coal seams in Haizi coal mine," Journal of China University of Mining \& Technology, vol. 31, no. 4, pp. 374-379, 2002.

[5] J. Z. Li, J. B. Zhang, J. L. Hou, and L. Wang, "Multiple disturbance instability mechanism of dynamic pressure roadway and mining sequence optimization," Journal of Mining and Safety Engineering, vol. 32, no. 3, pp. 439-445, 2015.

[6] S. Q. Li, Study on the coal and gas outburst mechanism and warning of close coal seams, Ph.D. dissertation, China University of Mining and Technology, Beijing, China, 2013.

[7] L. Xu, H. X. Wei, Z. Y. Xiao, and B. Li, "Engineering cases and characteristics of deviating stress under coal pillar in regional floor," Rock and Soil Mechanics, vol. 36, no. 2, pp. 561-568, 2015.

[8] S. X. Hu, X. L. Xu, S. H. Tian, and B. Zhang, "Optimization of roadway location-in lower coal seam from synergy mechanism of contiguous seam mining," Journal of Mining and Safety Engineering, vol. 33, no. 6, pp. 1008-1013, 2016.

[9] W. Zhang, D. S. Zhang, J. B. Chen, and X. F. Wang, "Determining the optimum gateway location for extremely close coal seams," Journal of China University of Mining \& Technology, vol. 41, no. 2, pp. 182-188, 2012. 
[10] R. Gao, B. Yu, and X. Meng, "Stress distribution and surrounding rock control of mining near to the overlying coal pillar in the working face," International Journal of Mining Science and Technology, vol. 29, no. 6, pp. 881-887, 2019.

[11] X. Gao, S. Zhang, Y. Zi, and S.-K. Pathan, "Study on optimum layout of roadway in close coal seam," Arabian Journal of Geosciences, vol. 13, no. 15, 2020.

[12] Y. Zhang, C. L. Zhang, C. C. Wei, Y. D. Liu, S. Q. Zhang, and J. J. Zhao, "The study on roadway layout in coordination of mining coal seams base on failure of floor strata," Advanced Materials Research, vol. 889-890, pp. 1362-1374, 2014.

[13] H. W. Wang, Y. D. Jiang, Y. X. Zhao, and T. Wang, "Determination of reasonable roadway position during extraction of closed coal seam based on energy theory," Chinese Journal of Rock Mechanics and Engineering, vol. 34, no. 2, pp. 40214029, 2015.

[14] C. G. Zhao, B. Bai, and Y. X. Wang, Principles of Soil Mechanics, Tsinghua University Press, Beijing, China, 2004.

[15] K. Terzaghi, R. B. Peck, and G. Meri, Soil Mechanics in Engineering Practice, John Wiley and Sons Inc, New York, NY, USA, 3rd edition, 1996.

[16] M. Budhu, Soil Mechanics and Foundations, John Wiley \& Sons, New York, NY, USA, 2000.

[17] W. J. Lei, G. H. Wang, and X. X. Xue, "Application of finite element strength reduction method to destruction in coal seam floor," Rock and Soil Mechanics, vol. 32, no. 1, pp. 299-303, 2011.

[18] M. G. Qian, P. W. Shi, and J. L. Xu, Mining Pressure and Strata Control, China University of Mining and Technology press, Xuzhou, China, 2010.

[19] Y. Yu, W. L. Shen, and J. Gao, "Deformation mechanism and control of lower seam roadway of contiguous seams," Journal of Mining and Safety Engineering, vol. 33, no. 1, pp. 49-55, 2016.

[20] B. F. Li, "Study on the stability of the surrounding rock for alternate exterior entry layout pattern in dynamic pressure area," Master dissertation, Taiyuan University of Technology, Taiyuan, China, 2001.

[21] J. C. Liu, "Research on roadway layout and support in thick seam layer mining," Master dissertation, China University of Mining and Technology, Xuzhou, China, 2016.

[22] B. N. Hu, "Stability analysis of coal pillar in strip mining," Journal of China Coal Society, vol. 20, no. 2, pp. 205-210, 1995.

[23] Z. L. Xu, Elasticity Mechanics, Higher Education Press, Beijing, China, 2013.

[24] L. Y. Zhang, "Study on the influence of macroscopic fracture on energy release of coal failure," Master dissertation, Liaoning Technical University, Fuxin, China, 2017.

[25] Y. X. Yu, D. Ke, J. B. Wang, and F. Y. Wang, "Discussion on determination method of the limit equilibrium zone width based on the deformation analysis of coal wall," Journal of China Coal Society, vol. 44, no. 11, pp. 3340-3348, 2019.

[26] Y. X. Yu, X. Hong, and F. F. Chen, "Study on load transmission mechanism and limit equilibrium zone of coal-wall in extraction opening," Journal of China Coal Society, vol. 37, no. 10, pp. 1630-1636, 2012.

[27] Z. Q. Ma, C. M. Tao, Y. J. Zuo, and G. Y. Wu, "Supporting technology of roadways with thick and soft roof based on energy balance theory," Journal of Mining and Safety Engineering, vol. 35, no. 3, pp. 496-502, 2018.

[28] K. Ma, L. M. Yin, J. T. Chen, and M. Chen, "Theoretical analysis on failure of water-resisting key strata in the floor by local high confined water in deep mining," Rock and Soil Mechanics, vol. 39, no. 9, pp. 3213-3222, 2018.
[29] K. Yang, S. Liu, C. A. Tang, and Z. Wei, "Mechanism and prevention of coal seam rib spalling in remote protected layer across coal group," Journal of China Coal Society, vol. 44, no. 9, pp. 2611-2621, 2019.

[30] Q. Ma, Y. Tan, X. Liu, Q. Gu, and X. Li, "Effect of coal thicknesses on energy evolution characteristics of roof rockcoal-floor rock sandwich composite structure and its damage constitutive model," Composites Part B: Engineering, vol. 198, Article ID 108086, 2020.

[31] S. L. Song, X. S. Liu, Y. L. Tan, D. Y. Fan, and Q. Ma, "Study on failure modes and energy evolution of coal-rock combination under cyclic loading," Shock and Vibration, vol. 2020, Article ID 5731721, 16 pages, 2020. 